\title{
High valuable compounds from the unripe peel of several Musa species cultivated in Madeira Island (Portugal)
}

\author{
Juan José Villaverde a,e ${ }^{\mathrm{a}}$ Lúcia Oliveira ${ }^{\mathrm{a}, \mathrm{b}}$, Carla Vilela ${ }^{\mathrm{a}}$, Rosário M. Domingues ${ }^{\mathrm{c}}$, Nélia Freitas ${ }^{\mathrm{d}}$, \\ Nereida Cordeiro $^{\mathrm{d}}$, Carmen S.R. Freire ${ }^{\mathrm{a}}$, Armando J.D. Silvestre ${ }^{\mathrm{a}, *}$ \\ a CICECO and Department of Chemistry, University of Aveiro, 3810-193 Aveiro, Portugal \\ ${ }^{\mathrm{b}}$ Regional Laboratory of Veterinary and Food Safety, Regional Directorate of Agriculture and Rural Development, 9000-254 Funchal, Portugal \\ c QOPNA and Department of Chemistry, University of Aveiro, 3810-193 Aveiro, Portugal \\ d Competence Centre in Exact Science and Engineering, University of Madeira, 9000-390 Funchal, Portugal \\ e DTEVPF - Unit of Plant Protection Products, INIA, Ctra. de La Coruña, Km. 7.5, 28040 Madrid, Spain
}

\section{A R T I C L E I N F O}

\section{Article history:}

Received 29 March 2012

Received in revised form 20 June 2012

Accepted 22 June 2012

\section{Keywords:}

Musa acuminata

Musa balbisiana

Hybrids

Unripe banana residues

GC-MS

Sterols

Lipophilic extractives

\begin{abstract}
A B S T R A C T
The lipophilic extractives of the unripe peel of ten banana cultivars belonging to the Musa acuminata and Musa balbisiana species (namely 'Giant Cavendish', 'Chinese Cavendish', 'Grand Nain', 'Gruesa', 'Williams', 'Ricasa', 'Eilon', 'Zelig', 'Dwarf Red' and 'Silver') were studied by gas chromatography-mass spectrometry. The extractives content were in the range of 2-3\% with substantially higher values for 'Silver' and 'Dwarf Red' (5.7 and $10.7 \%$ respectively). Sterols and fatty acids were the major families of compounds identified, with respectively $55.1-87.5 \%$ and $10.6-43.2 \%$ of total of lipophilic components. Cycloeucalenone was the main component identified in 'Williams' and 'Dwarf Red', with abundances ranging from 806 to $9453 \mathrm{mg} \mathrm{Kg}^{-1}$ of dry unripe peels, respectively. The identification of high contents of valuable compounds, can open new strategies for the valorization of the studied banana residues and particularly of those from 'Dwarf Red' followed by 'Silver' and 'Ricasa', as potential sources of high-value phytochemicals.
\end{abstract}

(C) 2012 Elsevier B.V. All rights reserved.

\section{Introduction}

Banana and plantain (Musa spp.) are major tropical and subtropical sources of food and raw materials. Bananas are cultivated in over 130 countries and grow over a harvested area of approximately 10 million hectares. The annual world production accounts for about 80 million tons, with India as the major producer with about 26 million tons (FAO, 2009).

The genus Musa is composed of four sections: Australimusa, Callimusa, Musa and Rhodochlam. Most edible bananas are originated from two species of the section Musa: M. acuminata and M. balbisiana. The cultivars are either hybrids among subspecies of $M$. acuminata (ploid type A) or between M. acuminata and M. balbisiana (ploid type $B$ ). The most important banana cultivars are triploid AAA and plantains are mostly AAB, ABB or BBB (Ball et al., 2006). Due to the difficulty of breeding infertile plants, only a few cultivars have been introduced in the last 50 years. The advent of clonal propagation, combined with selection programs, led to the singling out of "elite" clones in terms of yield and fruit quality, adapted to the agro-ecological conditions.

\footnotetext{
* Corresponding author. Tel.: +351 234370711; fax: +351234370084

E-mail address: armsil@ua.pt (A.J.D. Silvestre).
}

Banana crop was introduced in Madeira Island in the sixteenth century and nowadays banana plantations occupy about $11 \%$ of agricultural area and represent $20 \%$ of the agricultural production and $1 / 3$ of the exports of the Island. Finally, this plantation is currently considered as essential to protect the natural landscape of the region (Ribeiro and Silva, 1998).

The cultivar 'Dwarf Cavendish' is the most important, comprising ca. $60 \%$ of the total banana production in Madeira. However, recent changes in European Union Policies prompt farmers to select and grow other varieties (Council Regulation, 2006). As a response, new banana cultivars have been introduced in the region and some of them have already been released to farmers (Ribeiro and Silva, 1998).

After harvesting of the single bunch of bananas, a huge amount of residues are produced (banana plant and unripe banana residues). The banana plant residues (pseudostem, foliage, and rachis) are usually left in the soil plantation and used as fertilizer. The unripe banana residues are produced mainly during their selection process in the collection stations where the bananas too small for shipping or those with damaged or spoiled areas, are removed. These rejected bananas are normally improperly disposed, causing environmental problems. Different strategies have been suggested for the valorization of these wastes such as in flours, dried pulps, jams in animal feed or eventually composted (Zhang 
et al., 2005); for the production of biofuels (Bardiya and Somayaji, 1996; Hammond et al., 1996; Tewari et al., 1986), or as adsorbents for water purification (Annadurai et al., 2002, 2003). Finally, banana peel extracts were also used for phytopharmaceutical applications (Gene, 1999).

In a previous study, we reported a detailed study on the lipophilic extracts from unripe pulp and peel of banana fruit of 'Dwarf Cavendish' (Oliveira et al., 2008), where high amounts of fatty acids and particularly, free sterols, steryl esters, and steryl glucosides were found.

The importance of banana crops in Madeira Island and the detection of valuable compounds in 'Dwarf Cavendish' extracts (Oliveira et al., 2008), lead us to study new varieties introduced in Madeira Island in order to access their potential as sources of high value phytochemicals with nutraceutical applications. Banana peels lipophilic extracts from ten subspecies of $M$. acuminata (AAA) and hybrids from M. acuminata and M. balbisiana (AAB and ABB), namely 'Giant Cavendish', 'Chinese Cavendish', 'Grand Nain', 'Gruesa', 'Williams', 'Ricasa', Eilon', 'Zelig', 'Dwarf Red' and 'Silver' were surveyed in the present study by gas chromatography-mass spectrometry (GC-MS) analysis.

\section{Material and methods}

\subsection{Chemicals}

Dichloromethane (99\% purity), pyridine (99\% purity), $\mathrm{N}, \mathrm{O}$-bis(trimethylsilyl)trifluoroacetamide (99\% purity), trimethylchlorosilane (99\% purity), stigmasterol (95\% purity), octadecanoic acid (99\% purity), nonadecanol (99\% purity), coniferyl alcohol (98\% purity) and tetracosane (99\% purity) were supplied by Sigma Chemicals Co. (Madrid, Spain).

\subsection{Samples preparation}

Ten varieties of unripe bananas from the Bananiculture Center of the Regional Government, Lugar de Baixo, in the Madeira Island, were selected: 'Chinese Cavendish', 'Giant Cavendish', 'Dwarf Red', 'Grand Nain', 'Eilon', ‘Gruesa', 'Silver', 'Ricasa', 'Williams' and 'Zelig'. For each variety a minimum of 50 unripe fruits were collected. Peels were separated from the fruit, cut, lyophilized and milled to pass through a 40-60 mesh sieve.

\subsection{Extraction}

Three powdered samples ( $20 \mathrm{~g}$ ) of each cultivar were Soxhlet extracted with dichloromethane $(600 \mathrm{~mL})$ for $6 \mathrm{~h}$. The solvent was evaporated to dryness, the lipophilic extracts were weighed and the results were expressed in percent of dry material. Dichloromethane was selected as a fairly specific solvent for lipophilic extractives isolation for analytical purposes.

\subsection{GC-MS analysis}

Before GC-MS analysis, two aliquots of each dried extract (20 mg each) and an accurate amount of internal standard (tetracosane, $0.25-0.50 \mathrm{mg}$ ) were dissolved in $250 \mu \mathrm{l}$ of pyridine. The compounds containing hydroxyl and carboxyl groups were converted into trimethylsilyl (TMS) ethers and esters, respectively, by adding $250 \mu \mathrm{l}$ of $\mathrm{N}, \mathrm{O}$-bis(trimethylsilyl)trifluoroacetamide and $50 \mu \mathrm{l}$ of trimethylchlorosilane, standing the mixture at $70^{\circ} \mathrm{C}$ for $30 \mathrm{~min}$ (Freire et al., 2002a). The derivatized extracts were analyzed by GC-MS following previously described methodologies (Freire et al., 2002a; Oliveira et al., 2008) on a Trace Gas Chromatograph 2000 Series, equipped with a Thermo Scientific DSQII single-quadrupole mass spectrometer and a DB-1 J\&W capillary column ( $30 \mathrm{~m} \times 0.32 \mathrm{~mm}$ inner diameter, $0.25 \mu \mathrm{m}$ film thickness). The chromatographic conditions were as follows: initial temperature, $80^{\circ} \mathrm{C}$ for $5 \mathrm{~min}$; temperature gradient, $4{ }^{\circ} \mathrm{C} / \mathrm{min}$; final temperature, $260^{\circ} \mathrm{C}$; temperature gradient, $2^{\circ} \mathrm{C} / \mathrm{min}$; final temperature, $285^{\circ} \mathrm{C}$ for $8 \mathrm{~min}$; injector temperature, $250^{\circ} \mathrm{C}$; transfer-line temperature, $290^{\circ} \mathrm{C}$; split ratio, 1:33.

To check the presence of esterified structures, samples were also analyzed with a DB- $1 \mathrm{~J} \& \mathrm{~W}$ capillary column $(15 \mathrm{~m} \times 0.32 \mathrm{~mm}$ inner diameter, $0.25 \mu \mathrm{m}$ film thickness); the chromatographic conditions were as follows: initial temperature, $100^{\circ} \mathrm{C}$ for $3 \mathrm{~min}$; temperature gradient, $5^{\circ} \mathrm{C} / \mathrm{min}$; final temperature, $340^{\circ} \mathrm{C}$ for $12 \mathrm{~min}$; injector temperature, $290^{\circ} \mathrm{C}$; transfer-line temperature, $290^{\circ} \mathrm{C}$; split ratio, $1: 33$.

Compounds were identified as TMS derivatives by comparing their mass spectra with the GC-MS spectral library (Wiley-NIST Mass Spectral Library, 1999), their characteristic retention times obtained under the described experimental conditions (Oliveira et al., 2006, 2008), by comparing their fragmentation profiles with published data (Freire et al., 2002a; Oliveira et al., 2006, 2008; Villaverde et al., 2009 and references therein) and by injection of standards.

For semi-quantitative analysis, GC-MS was calibrated with pure reference compounds, representative of the major lipophilic extractive families (stigmasterol, octadecanoic acid, ferulic acid and nonadecan-1-ol), relative to tetracosane. The respective response factors were calculated as an average of six GC-MS runs. For tocopherols the response factor of stigmasterol was used. Each aliquot was injected in triplicate. The presented results are the average of the concordant values obtained for the six aliquots (less than $5 \%$ variation between injections of the same aliquot and between aliquots of the same banana variety extracts).

\section{Results and discussion}

The lipophilic extractives yields obtained for the banana peels from the different studied cultivars (Fig. 1) are in general very similar between them accounting for around 3\% of the dry material weight, with the exception of 'Williams', 'Silver' and 'Dwarf Red' cultivars that presented $2.0,5.7$ and $10.7 \%$ of lipophilic extractives, respectively. These values are generally in good agreement with those previously reported for other Musa varieties (Goldstein and Wick, 1969; Oliveira et al., 2006, 2008), although the high extractives content of 'Dwarf Red' is particularly worth of note in the context of this study.

The GC-MS analysis of the lipophilic extracts of the banana peels from the different cultivars shows that they are composed mainly by sterols, followed by fatty acids, aliphatic alcohols and $\alpha$-tocopherol (Fig. 2 and Table 1). Minor amounts of trans-ferulic acid were also detected in all samples. This composition and relative abundances are concordant with that reported for 'Dwarf Cavendish' (Oliveira et al., 2008). The relative abundance of the identified compounds and their families is in general very similar between all samples, except for 'Dwarf Red', Silver' and 'Ricasa' that presented higher sterols contents. Therefore, these results indicated that the Musa balbisiana cultivars ('Dwarf Red' and 'Silver') are richer in sterols than the Musa acuminata counterparts (the rest of studied species).

As already referred, sterols (Table 1 and Fig. 2) are the main class of compounds present in the unripe banana peels, with total contents between 55.1 and $87.5 \%$ of the total lipophilic extractives identified (2.8-12.4 g/ $\mathrm{kg}$ of dry material), with the extreme values recorded for 'Giant Cavendish' and 'Dwarf Red', respectively. Cycloeucalenone (Fig. 3) is the major component of this family identified in all peel samples, representing between 46.8 ('Gruesa') and 76.4\% ('Dwarf Red') of total sterols contents and 


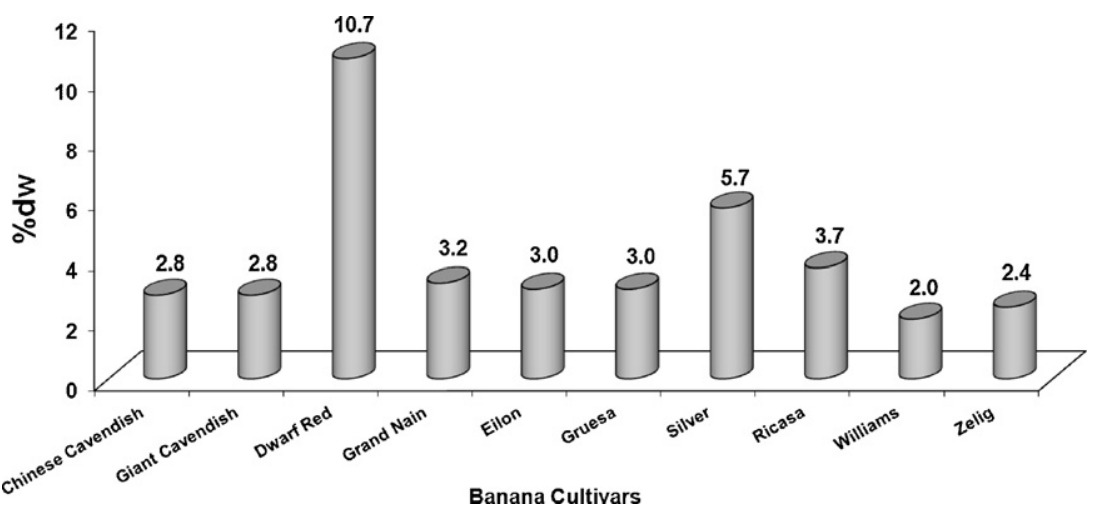

Fig. 1. Dichloromethane extractive yields in dry material \% for each unripe peel, from the studied cultivars.

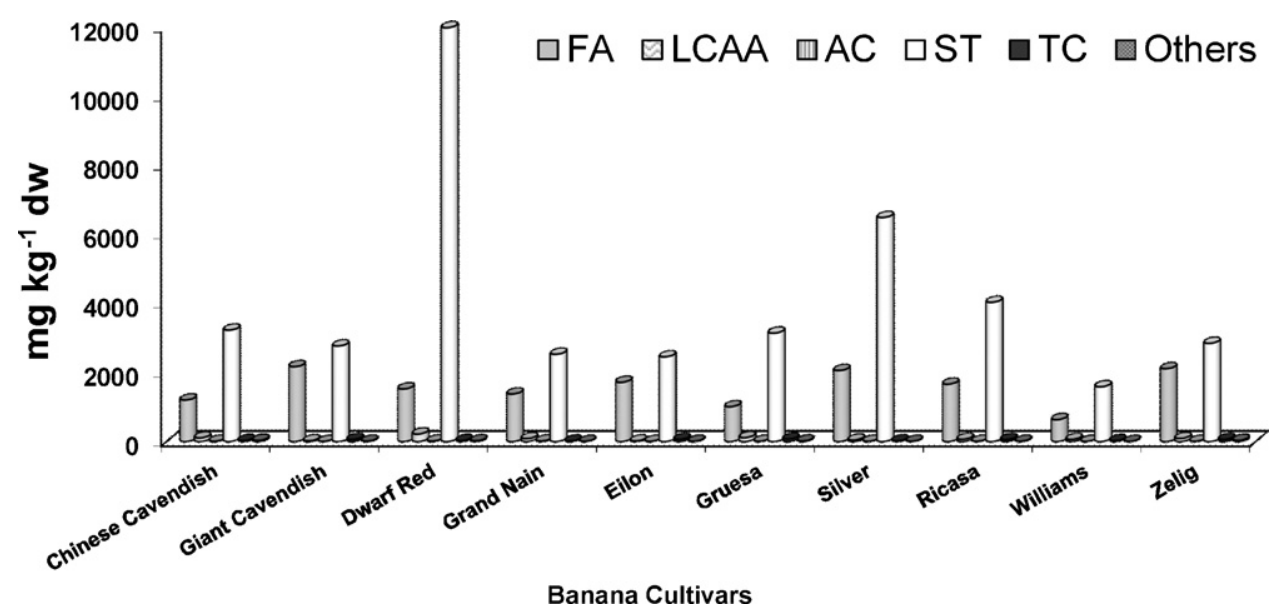

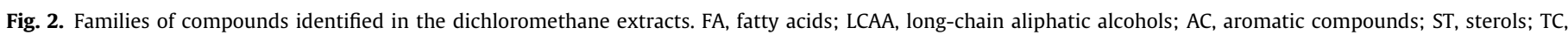
tocopherols.

between 26.8 ('Zelig') and 65.8\% ('Dwarf Red') of the total lipophilic extractives (Table 1). Other abundant identified sterols included 31norcyclolaudenone (199-1975 $\mathrm{mg} \mathrm{kg}^{-1}$ of extracts), stigmasterol (194-373 $\mathrm{mg} \mathrm{kg}^{-1}$ of extracts), $\beta$-sitosterol (269-601 $\mathrm{mg} \mathrm{kg}^{-1}$ of extracts), campesterol (110-741 $\mathrm{mg} \mathrm{kg}^{-1}$ of extracts) and smaller amounts of cycloeucalenol and cycloartenol (Fig. 3).

Cycloeucalenone and 31-norcyclolaudenone are two isomeric steroid ketones previously identified in banana peel, pulp, flowers, petioles/midrib, leaf blades/sheaths, floral stalk and rachis of some Musa species (Akihisa et al., 1986; Banerji et al., 1982; Knapp and Nicholas, 1969; Oliveira et al., 2006, 2008). In fact, these two compounds have been detected in the unripe peel of 'Dwarf Cavendish', as the most important exploitable compounds, with 6.5 and $2.1 \mathrm{~g} / \mathrm{kg}$ of dry material (Oliveira et al., 2008). $\beta$-sitosterol, stigmasterol and campesterol are also abundant sterols in all the studied banana peels (Table 1). These sterols are frequently found in tissues and

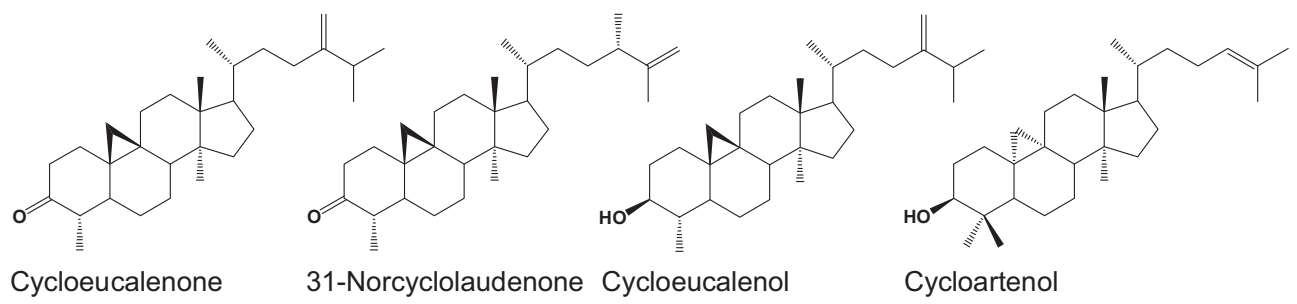

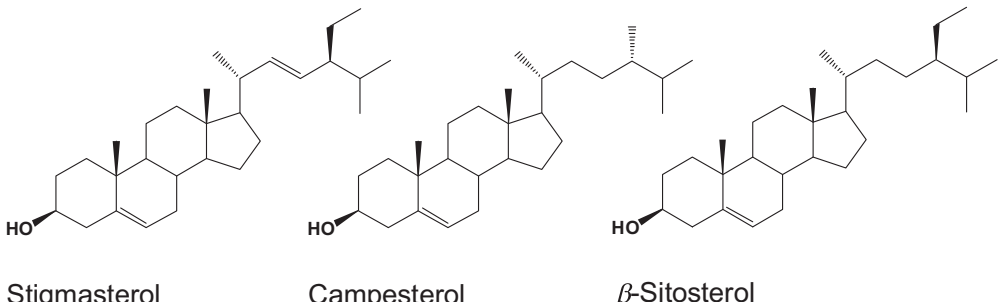

Fig. 3. Structures of the sterols identified in the cultivars studied. 
Table 1

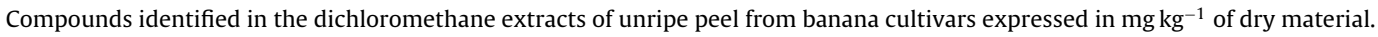

\begin{tabular}{|c|c|c|c|c|c|c|c|c|c|c|c|}
\hline $\mathrm{rt}(\mathrm{min})$ & Compound & 'Chinese Cavendish’ & 'Giant Cavendish' & 'Dwarf Red' & ‘Grand Nain’ & 'Eilon' & 'Gruesa' & 'Silver' & 'Ricasa' & 'Williams' & 'Zelig' \\
\hline & Fatty acids & 1207 & 2174 & 1528 & 1382 & 1723 & 1013 & 2064 & 1669 & 639 & 2116 \\
\hline & Saturated & 760 & 780 & 1057 & 506 & 599 & 550 & 1017 & 591 & 351 & 1146 \\
\hline 9.3 & Octanoic acid & 6 & 2 & 21 & 6 & 2 & 3 & 27 & 4 & 3 & 5 \\
\hline 11.5 & Dodecanoic acid & 3 & 3 & 22 & 6 & 3 & 5 & 11 & 6 & 3 & 4 \\
\hline 16.4 & Tetradecanoic acid & 7 & 6 & 22 & 7 & 9 & 9 & 13 & 13 & 5 & 9 \\
\hline 18.6 & Pentadecanoic acid & 14 & 15 & 11 & 10 & 13 & 9 & 14 & 15 & 7 & 20 \\
\hline 20.7 & Hexadecanoic acid & 533 & 588 & 582 & 373 & 446 & 328 & 752 & 418 & 244 & 803 \\
\hline 22.8 & Heptadecanoic acid & 24 & 16 & 11 & 18 & 15 & 22 & 14 & 17 & 9 & 30 \\
\hline 24.7 & Octadecanoic acid & 55 & 61 & 51 & 32 & 42 & 42 & 67 & 44 & 26 & 80 \\
\hline 26.6 & Nonadecanoic acid & 10 & 4 & 7 & 7 & 3 & 11 & 11 & 8 & 5 & 12 \\
\hline 28.4 & Eicosanoic acid & 22 & 30 & 23 & 0 & 28 & 55 & 20 & 26 & 20 & 89 \\
\hline 31.8 & Heneicosanoic acid & 11 & 8 & 33 & 15 & 6 & 11 & 18 & 10 & 2 & 11 \\
\hline 33.4 & Docosanoic acid & 8 & 5 & 11 & 4 & 3 & 8 & 6 & 5 & 2 & 9 \\
\hline 35.0 & Tricosanoic acid & 21 & 17 & 102 & 8 & 13 & 14 & 25 & 10 & 10 & 32 \\
\hline 36.5 & Tetracosanoic acid & 6 & 4 & 7 & 2 & 2 & 5 & 5 & 2 & 3 & 10 \\
\hline 38.0 & Pentacosanoic acid & 12 & 10 & 124 & 5 & 6 & 11 & 13 & 5 & 5 & 14 \\
\hline 39.4 & Hexacosanoic acid & 4 & 3 & 5 & 0 & 0 & 3 & 1 & 0 & 0 & 4 \\
\hline \multirow[t]{2}{*}{43.4} & Triacontanoic acid & 24 & 8 & 25 & 13 & 8 & 14 & 20 & 8 & 7 & 14 \\
\hline & Unsaturated & 430 & 1383 & 430 & 860 & 1118 & 442 & 1024 & 1065 & 281 & 959 \\
\hline 20.2 & Hexadec-9-enoic acid & 6 & 9 & 14 & 8 & 9 & 7 & 8 & 17 & 3 & 9 \\
\hline 23.9 & Octadeca-9,12-dienoic acid & 185 & 518 & 160 & 357 & 427 & 165 & 443 & 441 & 104 & 408 \\
\hline 24.0 & Octadeca-9,12,15-trienoic acid & 202 & 762 & 177 & 439 & 631 & 220 & 486 & 542 & 155 & 491 \\
\hline \multirow[t]{2}{*}{24.2} & Octadec-9-enoic acid & 37 & 94 & 79 & 56 & 51 & 48 & 87 & 65 & 19 & 51 \\
\hline & Diacids & 13 & 9 & 36 & 14 & 6 & 13 & 22 & 11 & 6 & 7 \\
\hline 15.4 & Nonadioic acid & 10 & 8 & 35 & 11 & 6 & 7 & 22 & 10 & 4 & 7 \\
\hline \multirow[t]{2}{*}{16.6} & Decanedioic acid & 3 & 1 & 1 & 3 & 0 & 6 & 0 & 1 & 2 & 0 \\
\hline & $\omega$-Hydroxy acids & 4 & 2 & 5 & 2 & 0 & 8 & 1 & 2 & 1 & 4 \\
\hline \multirow[t]{2}{*}{37.3} & 22-Hydroxydocosanoic acid & 4 & 2 & 5 & 2 & 0 & 8 & 1 & 2 & 1 & 4 \\
\hline & Long chain aliphatic alcohols & 107 & 20 & 220 & 86 & 16 & 114 & 44 & 65 & 62 & 91 \\
\hline 19.0 & Hexadecan-1-ol & 23 & 1 & 10 & 35 & 4 & 17 & 4 & 12 & 14 & 22 \\
\hline 22.4 & (Z)-octadec-9-en-1-ol & 48 & 2 & 4 & 14 & 2 & 43 & 4 & 5 & 32 & 40 \\
\hline 23.1 & Octadecan-1-ol & 16 & 1 & 1 & 22 & 2 & 20 & 4 & 34 & 9 & 13 \\
\hline 30.4 & Docosan-1-ol & 3 & 2 & 22 & 3 & 1 & 8 & 6 & 2 & 1 & 1 \\
\hline 33.7 & Tetracosan-1-ol & 5 & 3 & 130 & 4 & 2 & 8 & 11 & 4 & 1 & 4 \\
\hline \multirow[t]{2}{*}{39.6} & Octacosan-1-ol & 12 & 11 & 53 & 8 & 5 & 18 & 15 & 8 & 5 & 11 \\
\hline & Aromatic compounds & 8 & 3 & 14 & 15 & 6 & 7 & 7 & 8 & 2 & 5 \\
\hline \multirow[t]{2}{*}{21.6} & Trans ferulic acid & 8 & 3 & 14 & 15 & 6 & 7 & 7 & 8 & 2 & 5 \\
\hline & Sterols & 3238 & 2775 & 12,378 & 2535 & 2461 & 3149 & 6488 & 4025 & 1591 & 2854 \\
\hline 40.4 & Campesterol & 166 & 155 & 741 & 111 & 139 & 206 & 133 & 167 & 110 & 181 \\
\hline 41.0 & Stigmasterol & 328 & 272 & 206 & 211 & 250 & 373 & 198 & 304 & 194 & 334 \\
\hline 41.3 & 31-Norcyclolaudenone & 338 & 372 & 1357 & 371 & 351 & 474 & 1975 & 336 & 199 & 409 \\
\hline 41.5 & Cycloeucalenone & 1835 & 1484 & 9453 & 1397 & 1331 & 1473 & 3713 & 2569 & 806 & 1376 \\
\hline 41.8 & $\beta$-Sitosterol & 506 & 451 & 535 & 413 & 378 & 554 & 435 & 601 & 269 & 506 \\
\hline 42.3 & Cycloeucalenol & 31 & 20 & 86 & 32 & 5 & 32 & 34 & 23 & 7 & 26 \\
\hline \multirow[t]{2}{*}{42.4} & Cycloartenol & 34 & 21 & 0 & 0 & 7 & 37 & 0 & 25 & 6 & 22 \\
\hline & Tocopherols & 31 & 63 & 30 & 14 & 64 & 73 & 20 & 59 & 27 & 63 \\
\hline 39.1 & $\alpha$-Tocopherol & 31 & 63 & 30 & 14 & 64 & 73 & 20 & 59 & 27 & 63 \\
\hline
\end{tabular}

fruits of tropical plants, including bananas (del Río and Gutiérrez, 2006; Oliveira et al., 2006) and in plants in general.

Long chain fatty acids account for $639-2174 \mathrm{mg} \mathrm{kg}^{-1}$ of dry peels for 'Williams' and 'Giant Cavendish', respectively (Table 1 and Fig. 2). The identified components ranged from octanoic to triacontanoic acids, including four unsaturated structures (C16 and C18), two diacids (nonadioic and decanedioic acids) and an $\omega$-hydroxy fatty acid (Table 1 ). The presence of $\omega$-hydroxy fatty acids in banana peels has been previously reported in other Musa varieties (del Río and Gutiérrez, 2006; Oliveira et al., 2006). Hexadecanoic acid is the most abundant saturated fatty acid, with the highest content observed in the cultivar 'Zelig' ( $803 \mathrm{mg} \mathrm{kg}^{-1}$ of dry peel) and the lower in the 'Williams' ( $244 \mathrm{mg} \mathrm{kg}^{-} 1$ of dry peel). Regarding the unsaturated fatty acids, they found to be very abundant, especially in 'Giant Cavendish', 'Eilon', 'Ricasa' and 'Silver' banana peels, with $1383,1118,1065$ and $1024 \mathrm{mg} \mathrm{kg}^{-1}$ of dry material, respectively; highlighting the content of octadeca-9,12,15-trienoic (linolenic) acid ( $762 \mathrm{mg} \mathrm{kg}^{-1}$ of dry peel) in the 'Giant Cavendish'. Diacids and $\omega$-hydroxy acids were identified in minor amounts. In addition, a considerable number of odd numbered chain fatty acids, ranging from pentadecanoic acid to pentacosanoic acid, were also identified. Tricosanoic and pentacosanoic acids, in particular, were found among the major components in the 'Dwarf Red' peel, with 102 and $124 \mathrm{mg} \mathrm{kg}^{-1}$ of dry material, respectively. These compounds are frequently found in other plants belonging to the Musaceae family (del Río and Gutiérrez, 2006), and we have previously reported their presence in different morphological parts and fruits of 'Dwarf Cavendish', with values ranging from trace quantities for the nonanoic acid (in petioles/midrib, leaf blades, floral stalks, leaf sheaths and rachis) to $244 \mathrm{mg} \mathrm{kg}^{-1}$ of dry leaf blades 


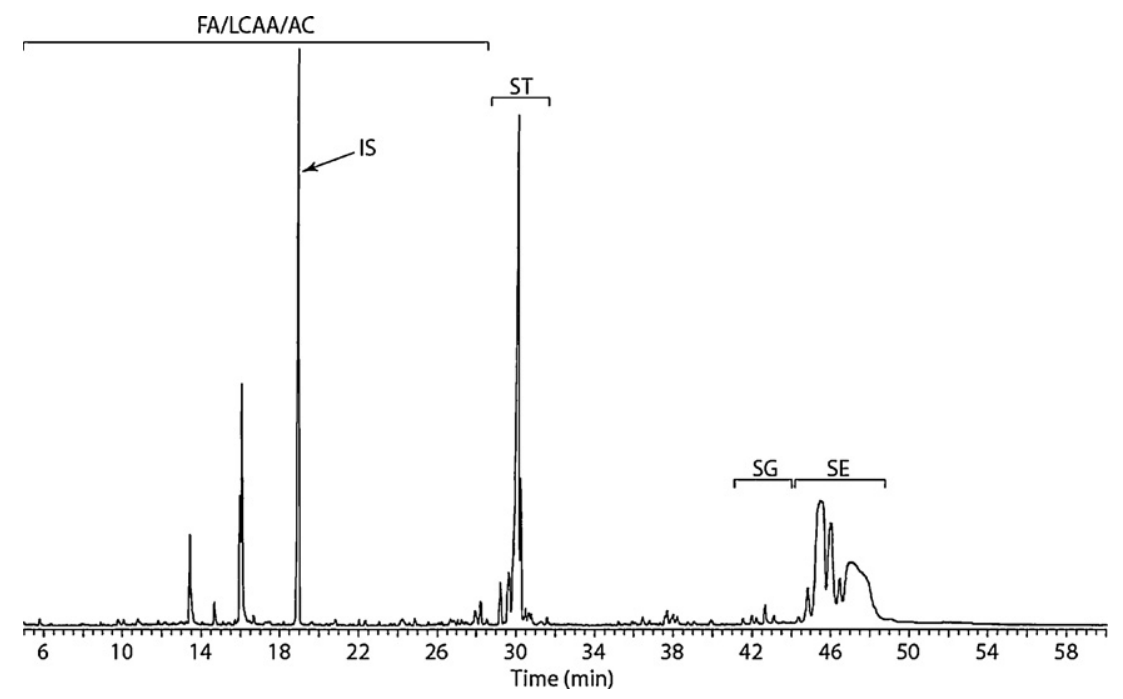

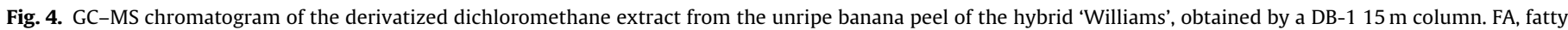
acids; LCAA, long-chain aliphatic alcohols; AC, aromatic compounds; ST, sterols; SG, steryl glucosides; SE, steryl esters; IS, internal standard.

for the pentacosanoic acid (Oliveira et al., 2006, 2008). These compounds are also quite common in other plants belonging to the Poaceae family (Coelho et al., 2007; Villaverde et al., 2009) or in the straw of different cereals (Sun and Sun, 2001; Xiao et al., 2001).

$\alpha$-Tocopherol, the most biologically active form of vitamin E, was the only tocopherol detected in the studied banana peels, accounting for $14-73 \mathrm{mg} \mathrm{kg}^{-1}$ of dry material (Table 1 ). The low content of tocopherols in these peel extracts is certainly associated with their low maturation state as previously reported for 'Dwarf Cavendish' where during the ripening process a significant increase in the tocopherols content can be observed which could attain up to $750 \mathrm{mg} \mathrm{kg}^{-1}$ of dry material (Oliveira et al., 2008). The same behavior was detected in other fruits (Moco et al., 2007).

Long-chain aliphatic alcohols (Table 1 and Fig. 2) represent between 16 and $220 \mathrm{mg} \mathrm{kg}^{-1}$ of dry peel. Only tetracosan-1-ol was identified in significant amounts $\left(130 \mathrm{mg} \mathrm{kg}^{-1}\right.$ of dry peel) in 'Dwarf Red'. 'Dwarf Cavendish' showed higher contents for this family (503 mg of compound/kg), with triacontan-1-ol as the most abundant compound with $156 \mathrm{mg} \mathrm{kg}^{-1}$ of dry peel (Oliveira et al., 2008).

In order to verify the presence of the esterified structures already reported for unripe, mature and defective banana fruits from 'Dwarf Cavendish' (Oliveira et al., 2005, 2008), the lipophilic extracts of all banana peels were also analyzed by GC-MS with a short length $(15 \mathrm{~m})$ column, using chromatographic conditions that enable the elution and detection of such low-volatile lipophilic compounds (Freire et al., 2002b): steryl glucosides, namely campesteryl $3 \beta$-Dglucopyranose, stigmasteryl $3 \beta$-D-glucopyranoside and sitosteryl $3 \beta$-D-glucopyranoside at rt 42.0, 42.2 and 42.7 , were only detected in small amounts, and broad peaks corresponding to mixtures of steryl esters were found to be considerably abundant (Fig. 4).

\section{Conclusion}

From the chemical composition described above, the unripe peels residues and particularly those from 'Dwarf Red', followed by 'Silver' and 'Ricasa' are abundant sources of phytosterols.

Considering that the sterol family has a wide variety of nutraceutical applications, such as reducing the cholesterol absorption and its blood levels (Quílez et al., 2003) and that those residues are generated in large quantities in the tropical regions where Musa species are cultivated level, the exploitation of these abundant components could be a relevant contribution to their valorization.
However, environmental regulations will require for their industrial exploitation the choice of more environmentally friendly extraction systems, such as supercritical $\mathrm{CO}_{2}$ extraction, which is seen as a good alternative for this type of compounds (Reverchon and De Marco, 2006) and is being considered in another study which will also address the selective isolation of the steryl esters fraction mentioned above. Finally, under these conditions the remaining residues could still be exploited for other applications, including energy conversion.

\section{Acknowledgments}

The authors wish to thank to Madeira Bananiculture Center for kindly providing the samples. To CICECO (PestC/CTM/LA0011/2011), QOPNA (PEst-C/QUI/UI0062/2011) for financial support. Juan José Villaverde also thanks FCT-Fundação para a Ciência e a Tecnologia for the awarding of a postdoctoral grant (BPD/UI89/4520/2009).

\section{References}

Akihisa, T., Shimizu, N., Tamura, T., Matsumoto, T., 1986. (24S)-14 $\alpha, 24$-dimethyl$9 \beta, 19$-cyclo-5 $\alpha$-cholest-25-en-3 $\beta$-ol: a new sterol and other sterols in Musa sapentium. Lipids 21, 494-497.

Annadurai, G., Juang, R-S., Lee, D-J., 2002. Use of cellulose-based wastes for adsorption of dyes from aqueous solutions. J. Hazard. Mater. 92, 263-274.

Annadurai, G., Juang, R-S., Lee, D-J., 2003. Adsorption of heavy metals from water using banana and orange peels. Water Sci. Technol. 47, 185-190.

Ball, T., Vrydaghs, L., Van Den Hauwe, I., Manwaring, J., De Langhe, E., 2006. Differentiating banana phitoliths: wild and edible Musa acuminata and Musa balbisiana. J. Archaeol. Sci. 33, 1228-1236.

Banerji, N., Sen, A.K., Das, A.K., 1982. A new 9,19-cyclotriterpene from flowers of Musa paradisiaca (banana). Indian J. Chem. 21B, 387-388.

Bardiya, N., Somayaji, K., 1996. Biomethanation of banana peel and pineapple waste. Bioresour. Technol. 58, 73-76.

Coelho, D., Marques, G., Gutiérrez, A., Silvestre, A.J.D., del Río, J.C., 2007. Chemical characterization of the lipophilic fraction of giant reed (Arundo donax) fibres used for pulp and paper manufacturing. Ind. Crops Prod. 26, 229-236.

del Río, J.C., Gutiérrez, A., 2006. Chemical composition of Abaca (Musa textiles) leaf fibers used for manufacturing of high quality paper pulps. J. Agric. Food Chem. 54, 4600-4610.

Council Regulation (EC) No. 2013/2006 (OJ No. L 384, 29.12.2006), pp. 13-19.

FAO (Food and Agriculture Organization) 2009; http://faostat.fao.org/.

Freire, C.S.R., Silvestre, A.J.D., Neto, C.P., Cavaleiro, J.A.S., 2002a. Lipophilic extractives of the inner and outer barks of Eucalyptus globulus. Holzforschung 56, 372-379.

Freire, C.S.R., Silvestre, A.J.D., Neto, C.P., 2002b. Identification of new hydroxy fatty acids and ferulic acid esters in the wood of Eucalyptus globulus. Holzforschung 56, 143-149. 
Gene, E.B., 1999. Banana peel extract composition and method for extraction, W09938479.

Goldstein, J.L., Wick, E.L., 1969. Lipid in ripening banana fruit. J. Food Sci. 34, 482-484.

Hammond, J.B., Egg, R., Diggins, D., Cable, C.G., 1996. Alcohol from bananas. Bioresour. Technol. 56, 125-130.

Knapp, F.F., Nicholas, H.J., 1969. The sterols and triterpenes of banana peel. Phytochemistry 8, 207-214.

Moco, S., Capanoglu, E., Tikunov, Y., Bino, R.J., Boyacioglu, D., Hall, R.D., Vervoort, J., De Vos, R.C.H., 2007. Tissue specialization at the metabolite level is perceived during the development of tomato fruit. J. Exp. Bot. 58, 4131-4146.

Oliveira, L., Freire, C.S.R., Silvestre, A.J.D., Cordeiro, N., 2008. Lipophilic extracts from banana fruit residues: a source of valuable phytosterols. J. Agric. Food Chem. 56, 9520-9524.

Oliveira, L., Freire, C.S.R., Silvestre, A.J.D., Cordeiro, N., Torres, I.C., Evtuguin, D., 2006. Lipophilic extractives from different morphological parts of banana plant Dwarf Cavendish. Ind. Crops Prod. 23, 201-211.

Oliveira, L., Freire, C.S.R., Silvestre, A.J.D., Cordeiro, N., Torres, I.C., Evtuguin, D., 2005. Steryl glucosides from banana plant Musa acuminate Colla var cavendish. Ind. Crops Prod. 22, 187-192.

Quílez, J., García-Lorda, P., Salas-Salvadó, J., 2003. Potential uses and benefits of phytosterols in diet: present situation and future directions. Clin. Nutr. 22, 343-351.
Reverchon, E., De Marco, I., 2006. Supercritical fluid extraction and fractionation of natural matter. J. Supercrit. Fluids 38, 146-166.

Ribeiro, L., Silva, A., 1998. Preliminary studies of cavendish banana cultivars under the edafoclimatic conditions of Madeira Island. In: Saúco, V.G.(Ed.), Proceedings of the I International Symposium on Banana in the Subtropics, Puerto de la Cruz, Tenerife, Spain. Acta Hortic. 490, 85-88.

Sun, R.C., Sun, X.F., 2001. Identification and quantification of lipophilic extractives from wheat straw. Ind. Crops Prod. 14, 51-64.

Tewari, H.K., Marwaha, S.S., Rupal, K., 1986. Ethanol from banana peels. Agric. Wastes $16(2), 135-146$.

Villaverde, J.J., Domingues, R.M.A., Freire, C.S.R., Silvestre, A.J.D., Pascoal Neto, C., Ligero, P., Vega, A., 2009. Miscanthus $\times$ giganteus extractives: a source of valuable phenolic compounds and sterols. J. Agric. Food Chem. 57, 36263631.

Xiao, B., Sun, X.F., Sun, R.C., 2001. Extraction and characterization of lipophilic extractives from rice straw. Part I: chemical composition. J. Wood Chem. Technol. 21, 397-411.

Zhang, P., Whistler, R.L., BeMiller, J.N., Hamaker, B.R., 2005. Banana starch: production, physicochemical properties, and digestibilitys. A review. Carbohydr. Polym. $59,443-458$. 